\title{
THE OPEN SOLUTION METHODOLOGY APPROACH TO PROBLEM SOLVING
}

\author{
ACJ van Rensburg \\ SJ Claasen \\ Department of Industrial and Systems Engineering \\ University of Pretoria
}

\begin{abstract}
The Open Solution Methodology is a generic problem solving methodology which is used to solve system related problems through the application of problem solving techniques. The focus of the application of this methodology is aimed at modelling organisations, or areas within organisations. The application of the Open Solution Methodology provides the benefit of having the ability to comprehend and integrate all aspects of the system, while having a formal and structured approach for problem solving. Together with the reduction in system analysis time, problem solving techniques such as simulation modelling are focused through the Open Solution Methodology models to enhance the quality of solutions.
\end{abstract}

\section{OPSOMMING}

Die "Open Solution Methodology" is " $n$ generiese probleemoplossingsmetodologie wat gebruik word om stelselverwante probleme op te los deur die toepassing van problemoplossingstegnieke. Die fokus van hierdie metodologie toepassing is gemik op die modellering van organisasies, of gedeeltes van organisasies. Die "Open Solution Methodology" toepassing verskaf die voordeel om alle aspekte van die stelsel te verstaan en te integreer, terwyl daar van ' $n$ formele en gestruktureerde benadering tot probleemoplossing gebruik gemaak word. Tesame met die gepaardgaande verkorting van stelselanalisetyd, word die "Open Solution Methodology" modelle gebruik om die toepassing van probleemoplossingstegnieke te fokus om sodoende kwaliteit van die oplossings te verhoog. 


\section{INTRODUCTION}

This research originates from the requirement to model organisations or areas within organisations as systems. In the modelling process models are built which incorporates the system's components and relationships in their natural states. Through the understanding gained, system related problems are resolved by the application of appropriate problem solving techniques. A generic problem solving methodology which formalizes this approach is presented as the Open Solution Methodology.

The Open Solution Methodology is based on a number of characteristics, concepts, guidelines, phases and models taken from existing methodologies such as the Soft Systems Methodology, IDEF and Information Engineering. The result is a methodology which provides the ability to model the components of a system, integrate these models with solution techniques, develop solutions, and implement the selected solutions. This approach differs from current problem solving methodologies which employ predefined solution techniques based on predefined relationships to resolve problems.

\section{THE APPROACH TO PROBLEM SOLVING}

People play the role of managers in their private and corporate environments - always busy trying to improve situations which are seen as problematical, or less than perfect. Thus to manage everyday life is to try and cope with a flux of interacting events and ideas as they evolve through time - changing yesterday's small hitches into today's big headaches. For the organisation and its employees survival in a complex business environment depends on how well these problems are understood and how well they are reacted to. The history of problem solving visible through lectures, conference papers and articles, show that a feasible method for finding solutions to problems is to build models of real-world situations. These real-world models, whether they are simple equations or complex dynamic simulation models, enable the analyst to observe and understand the basic concepts of the problem he is trying to solve [2].

The use of models to understand and solve problems is similar to the way in which the human brain digests complex problems. According to Harry [4], a mental model built by the human brain consists of carefully selected information while unnecessary features, not needed for our understanding, are blocked from the model itself. Thus, the use of models is of crucial importance in our understanding because it presents abstract views of how complex realworld situations function [7].

A problem-solving approach is the manner in which an analyst solves problems. This entails observing the problem environment, building models from these observations, designing 
solutions from the models, and implementing these solutions to solve the problem. Whether this problem-solving approach is applied in a formal or ad hoc manner, it forms a problemsolving methodology which consists of various qualitative and quantitative methods and techniques for problem solving.

\section{DEFINITION OF A METHODOLOGY}

Before the Open Solution Methodology is discussed, the terms methodology and method are defined. The term methodology refers to a collection of methods and techniques, whose use is governed by a process superimposed on the whole [3]. The methods and techniques contained within such a methodology are the operational procedures which describe how specific methodology functions need to be completed.

A method is based on the interaction of three processes, the "Definition" process, the "Discipline" process and the "Use" process. The operational interaction of these three processes orients them as a formally organised, single-purpose discipline contained within the method [6]. The basic intuitions and motivations behind the method are specified by the "Definition" process and include the method's concepts and operations. The "Discipline" process contains the language used to describe these concepts and operations together with the manner in which the method is applied. The Use activity focuses on the context-specific application of the method [4].

Methods incorporated into a methodology via the "Definition" process, the "Discipline" process and the "Use" process, provide the practitioner of a methodology with a reliable process of achieving consistently good results. This does not imply that the methodology itself provides the answers, but rather that the success lies in the ability of the analyst to understand and use the different methods and techniques involved.

\section{COMPONENTS OF A PROBLEM-SOLVING METHODOLOGY}

The study of a number of problem solving methodologies such as Information Engineering, Soft Systems Methodology, Structured analysis, Process-based modelling, Object Orientation, and Integrated Definition Language shows that the components of a generic problem-solving methodology can be classified as problem-solving characteristics, modelling guidelines, methods, models, and problem solving phases. 


\subsection{Problem-solving Characteristics}

Problem-solving characteristics are those characteristics which need to be present in a problem-solving methodology in order to model and solve problems. They are:

i) The problem goal which explains the reason of addressing the specific problem.

ii) The view which defines a particular view of the problem on which all relevant parties agree upon.

iii) The boundary which defines the boundary between the problem under study and its interaction with the external environment.

iv) Components which define the main problem components and subproblem components of the problem.

v) Hierarchy which displays the relations between the problem's subproblems and problem components.

vi) Control activities which describe the form of control over the components of the problem.

vii) Communication activities which describe the communication between the components of the problem, as well as the communication between the problem and its external environment.

\subsection{Modelling Guidelines}

Modelling guidelines are guidelines based on common problem-solving characteristics which form the foundation for modelling problem environments [10]. A generic problem-solving methodology references the following modelling guidelines in order to solve problems successfully, namely:

i) Modelling relies on a team approach.

ii) Functional expertise is included in the team.

iii) A complex problem is modelled with a number of modelling concepts.

iv) A problem consists of activities which transform input into output.

v) An activity is subject to control.

vi) A problem environment contains objects.

vi) Objects have relationships with other objects in the problem environment.

vii) Activities form a process.

viii) Processes are decomposed to lower level processes.

ix) Activities and processes involve objects.

$\mathrm{x}$ The modelling language uses verbs, nouns and pictures. 


\subsection{Methods}

As was discussed in paragraph 3, methods provide the operational procedures for the problem-solving methodology with the aim of producing models of the problem environment. Methods are in general methodology specific; methods for the Open Solution Methodology are discussed in paragraph 5.3.

\subsection{Models}

Models provide the means to model a problem through concepts such as activities, objects, processes, input, output, controls, and enablers. In essence, all of these are included in one of three models, the activity model, object model, and process model. Although each of these models focuses on different aspects of the problem, they form one integrated view of the problem by extracting the "what?", "how?", and "who?" from the problem environment (Figure 1).

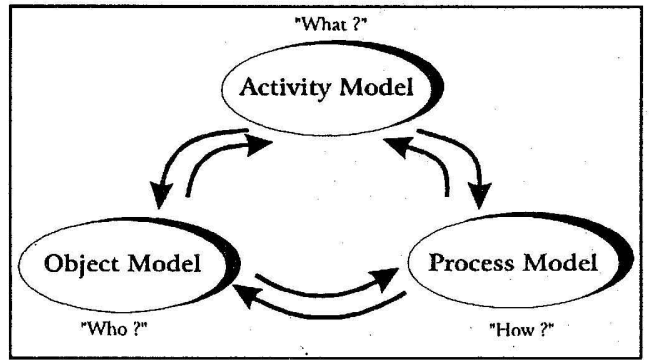

Figure 1 Problem-solving Models

\section{The Activity Model}

The aim of the activity model is to capture and model the transformation processes (the "what?") of the problem environment. The modelling of this "what?" is based on transformation processes which convert input into output. These transformation processes are enabled by enablers, while taking place under a set of controls.

\section{The Object Model}

The Object Model represents the "who?" in the problem environment. In order to model the "who?" the Object Model uses objects, object relationships, and object attributes.

\section{The Process Model}

The Process model defines "how?" the "what?" is achieved. This is done by describing the tasks needed to complete the activity through sequence, logic and objects. 


\subsection{Problem-Solving Phases}

Problem-solving phases are distinct phases which are completed in order to model the problem, with each phase consisting of a number of methods and models. Generally, problem-solving methodologies have three distinct problem-solving phases, namely an analysis phase, design phase, and implementation phase (Figure 2).

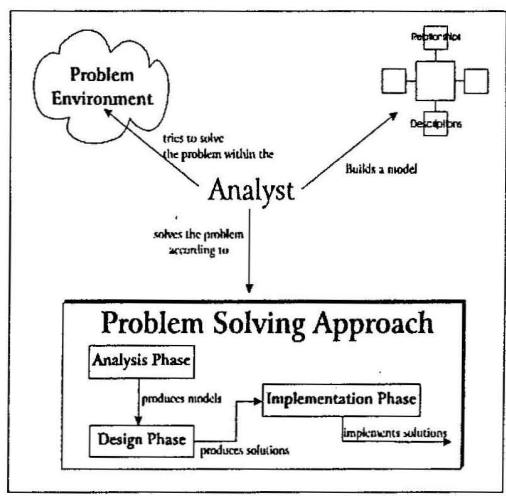

Figure 2 Problem-solving Phases

\section{THE OPEN SOLUTION METHODOLOGY}

The Open Solution Methodology is explained through its problem-solving phases, models, and methods.

\subsection{The Open Solution Methodology Phases}

The Open Solution Methodology consists of three problem-solving phases, the Analysis Phase, the Design Phase, and the Implementation Phase.

The Analysis Phase divides into four sub-phases, being the Definition Phase, Identification Phase, Specification Phase, and the Integration Phase. The Definition Phase provides the analyst with insight into the definition of the problem's goals in order to answer "Why are we studying the problem and what questions do we hope to answer?" $[8,9]$. This places the emphasis on problem definition as the crucial component in the overall methodology as it directly affects the credibility and acceptability of model results. The Identification Phase is the phase in which the analyst and the team build a problem definition by means of conceptual modelling. This entails the identification of the features of the problem which are sufficient to serve the objectives of the study. Included in the features are the problem components, significant problem activities and the problem hierarchy. The Specification Phase entails the 
development of an activity model to represent the problem's input, output, enablers and controls. The Integration Phase uses the Specification Phases' activity models to formulate the object model and the process model. The Design and Implementation Phases depend on the models developed during the Analysis Phase. In the Design Phase, the activity model, process model and object model are used to develop solutions for the problem environment, while solutions from these models are implemented during the Implementation Phase.

\subsection{The Open Solution Methodology Models}

The Open Solution Methodology uses three models to model problem environments, namely the activity model, process model, and object model. Figure 3, Figure 4 and Figure 5 displays the Open Solution Methodology models with their modelling elements and modelling relationships (Figure 5's UOB- "Unit of behaviour" refer to the process description of an activity).

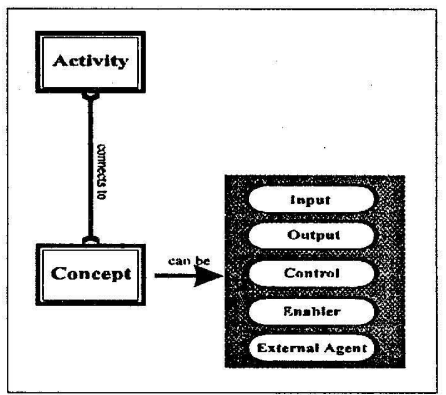

Figure 3 The Activity Model

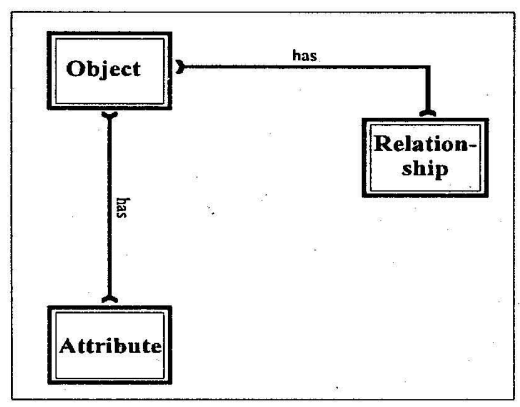

Figure 4 The Object Model

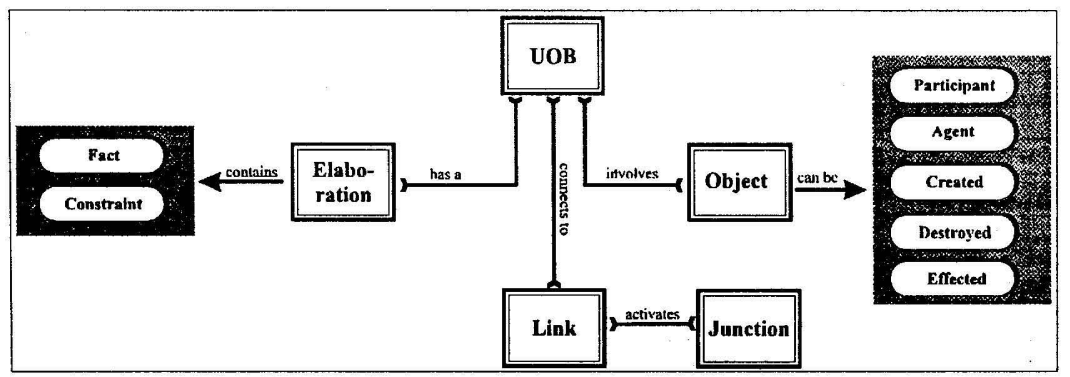

Figure 5 The Process Model 


\subsection{The Open Solution Methodology Framework}

Table 1 and Table 2 displays the relationships between the Open Solution Methodology's problem-solving phases and models.

\begin{tabular}{|c|c|c|}
\hline THE OPEN SOLUHONMBTHODOYOGY & AIM & MODEL: \\
\hline \multicolumn{3}{|l|}{ I. WNAGSISPALSE } \\
\hline $\begin{array}{l}\text { DEFINITION PHASE } \\
\text { a) Establish the purpose of the problem-solving exercise. } \\
\text { b) Define the world view on the problem. } \\
\text { c) Define the context of the problem environment. }\end{array}$ & $\begin{array}{l}\text { Discover the "what?" } \\
\text { of the problem. }\end{array}$ & $\begin{array}{l}\text { A c t i vity } \\
\text { Model }\end{array}$ \\
\hline $\begin{array}{l}\text { IDENTIFICATION PHASE } \\
\text { a) Identify problem components. } \\
\text { b) Identify the activities in the problem environment. } \\
\text { c) Build problem hierarchy. }\end{array}$ & $\begin{array}{l}\text { Discover the "what?" } \\
\text { of the problem. }\end{array}$ & $\begin{array}{l}\text { Activity } \\
\text { Model }\end{array}$ \\
\hline
\end{tabular}

Table 1 The Open Solution Methodology Framework

The framework for the Open Solution Methodology (phases and models) provides the structure for solving problems, but still lacks problem-solving methods.

\subsection{The Open Solution Methodology Methods}

Methods for the Open Solution Methodology are defined according to the Definition Phase, Identification Phase, Specification Phase, and Integration Phase.

\section{The Definition Phase}

The Definition Phase aim is to identify the reason and scope for the problem-solving exercise by extracting the "what?" from the problem environment. The Purpose Definition, World View Definition, Context Definition and Context Diagram are methods executed to:

i) Identify the modelling purpose.

ii) Identify the modelling viewpoint.

iii) Define the model boundary.

iv) Define a single activity that represents the entire subject under study.

v) Identify the role players in the problem environment. 


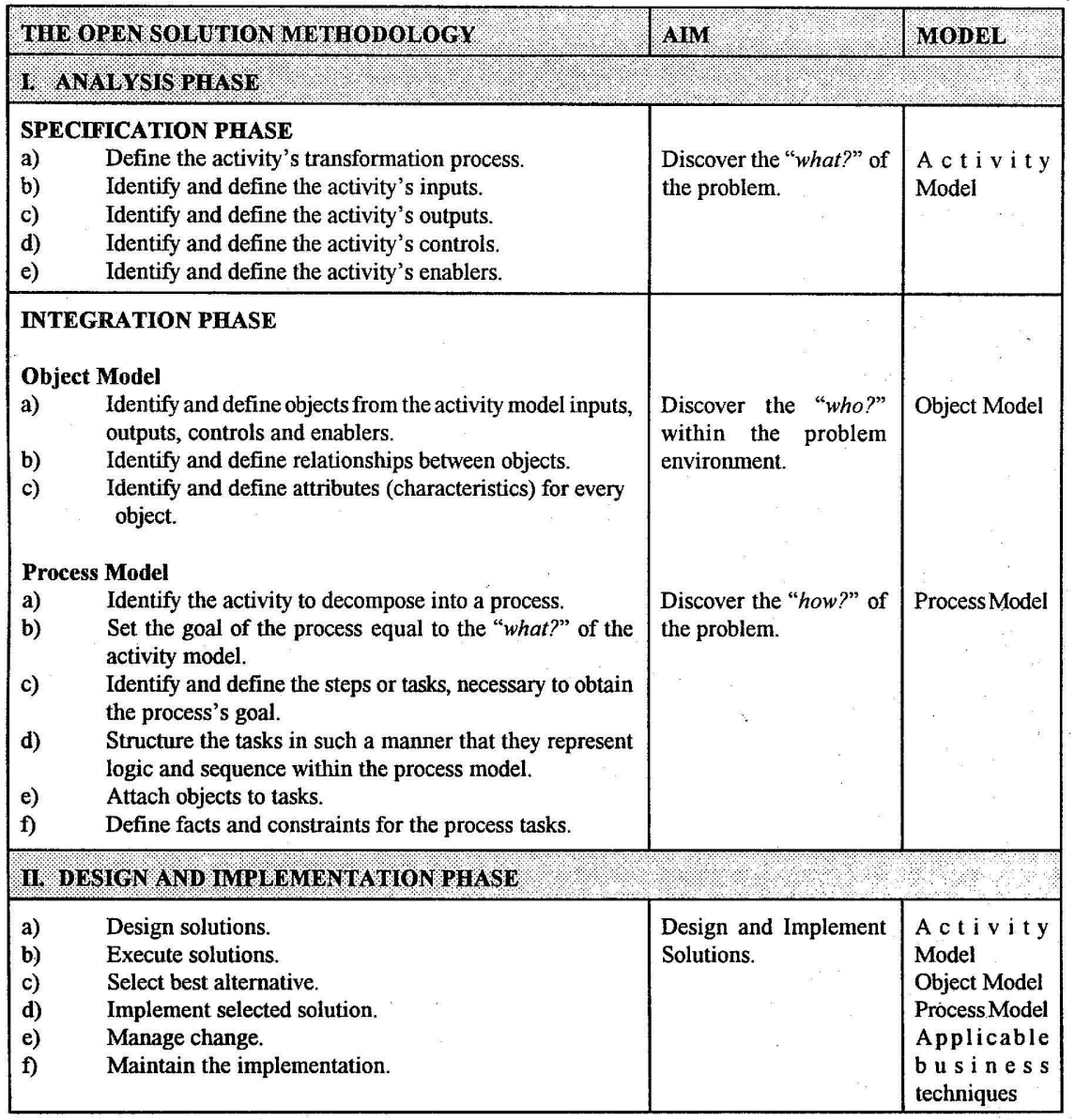

Table 2 The Open Solution Methodology Framework

\section{The Identification Phase}

The Identification Phase aim is to build a problem hierarchy which consists of the problem's main activities. The Node Diagram method is executed in this phase to: 
i) Gather information on the problem's important components.

ii) Define important activities within the problem environment.

iii) Obtain a preliminary understanding of the problem structure.

\section{The Specification Phase}

The Specification Phase aim is to identify and refine the activity detail of the problem. The Decomposition Diagram method is used to:

i) Decompose the parent activity into child activities.

ii) Gather insight into the resources needed by the activity to complete its transformation process.

iii) Gather insight into the products and services produced by the activity.

iv) Identify the measures by which an activity's transformation process is controlled.

v) Identify resources that enable the activity's transformation process.

\section{The Integration Phase}

The Integration Phase aim is to identify "how?" the "what?" is done, and "who?" does the"what?". The View Diagram and Scenario Diagram methods are used to:

i) Identify the "who?" of the problem through:

a) Identifying objects which represent the problem environment instances which the analyst needs to keep information about.

b) Defining relationships between objects.

c) Identifying relevant characteristics about the object.

ii) Identify "how?" the "what?" is accomplished through:

a) Defining the process goal in order to achieve the "what?".

b) Identifying the necessary tasks to be performed in order to achieve the process goal.

c) Arranging tasks in order to represent process sequence and logic.

d) Assigning process roles to objects.

e) Defining the constraints which govern the execution of process tasks. 


\section{T THE OPEN SOLUTION METHODOLOGY AND BUSINESS TECHNIQUES}

One of the Open Solution Methodology's goals is to be able to generate solutions for analysed problems in the Design Phase. This phase is seen as that part of the Open Solution Methodology where the "openness" and "connectivity" of the Open Solution Methodology are used to integrate business techniques with the Open Solution Methodology models in order to produce solutions (Figure 6). Some of these business techniques include simulation modelling, organisation design, data modelling, business process reengineering, activity-based costing and Total Quality improvement.

\section{APPLICATION EXAMPLE}

In order to demonstrate the application of the Open Solution Methodology an example is discussed which covers the improvement of a business process which deals with the processing of claims at a short term insurer's head office. The claim process consists of three sub-activities, namely the application process, evaluation process, and the approval process. Claims are submitted at branch level, from whereon it is send to head office. The claim officer receives the claim application, evaluates the claim application, approves the claim application upon which the administration department is instructed to pay the claim.

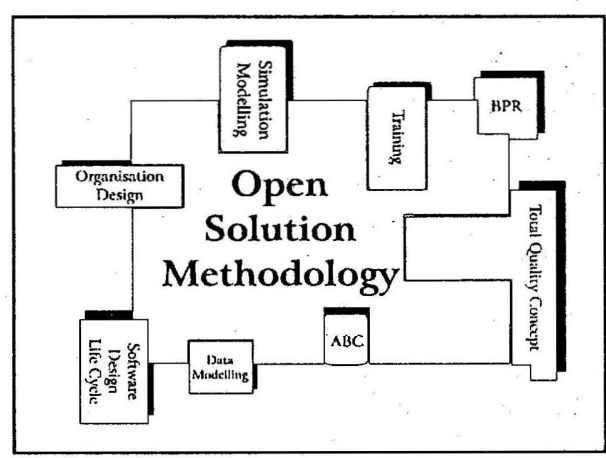

Figure 6 Integrating the Open Solution Methodology with Business Techniques

The Open Solution Methodology phases are used to illustrate the example.

\subsection{The Open Solution Methodology Analysis Phase}

i) Definition Phase

The Definition Phase of the Open Solution Methodology produces the following deliverables: 
a) Purpose Definition

The purpose of this model is to explain the process of completing claims.

b) World-View Definition

The viewpoint of the model is from the perspective of the claim officer.

c) Context Definition

The model is built in the context of the claims department.

d) Context Diagram Activity

Context Diagram Activity Name: Process Claims

Context Diagram Description:

Process Claims is the process which describes the processing of claim applications, including receiving the claim application, compiling the claim application reportand subsequently, payment of successful claims. This also includes the update of the client's history whenever a claim is lodged at $A B C$ Insurers.

e) External Agents

The Client, Branch Manager, and Police are external agents which interact with the claim process.

\section{ii) Identification Phase}

On completion of the Definition Phase, the Identification Phase is started and completed delivering the following:

a) Identification of Main Components

1) Claim applications are received.

2) Payments are prepared

3) The client's history is updated.

b) Identification of Activities

1) "Receive Claim Applications" decomposed into the following child activities:

- The claim application report is compiled.

- The claim application details are checked.

- The client is contacted.

- The claim application form is verified.

2) "Prepare payments"

3) "Update client history"

c) Definition of the Problem Hierarchy 
Table 3 illustrates the problem hierarchy as defined through the Node Diagram.

\begin{tabular}{|l|llll|}
\hline & & The Process Claim Hierarchy & . \\
\hline Level 1 & A0 & Process & Claims & \\
Level 2 & & A1 & Receive Claim Application \\
Level 3 & & & A11 & Compile Claim Application \\
Level 3 & & & A12 & Check Application Detail \\
Level 3 & & & A13 & Contact Client \\
Level 3 & & & A14 & Verify Claim Application Form \\
Level 2 & & A2 & Prepare Payment \\
Level 2 & & A3 & Update Client History \\
\hline
\end{tabular}

Table 3 The Node Diagram

iii) The Specification Phase

Based on the Identification Phase results, the Context Activity, Node Diagram, Activity Definitions, and Concept Definitions are used to define child activities from parent activities until a sufficient level of detail is reached. Figure 7 displays the Context Activity which describes the claim application on a high level.

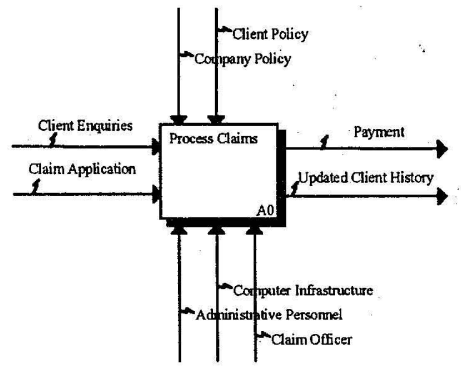

Figure 7 The Context Activity

iv) The Integration Phase

Whereas the Specification Phase produces activity models, the Integration Phase produces object models and process models of the claim application process.

a) The Object Model

The Object Model models the "who" involved in the in the claim application process (Figure 8). 


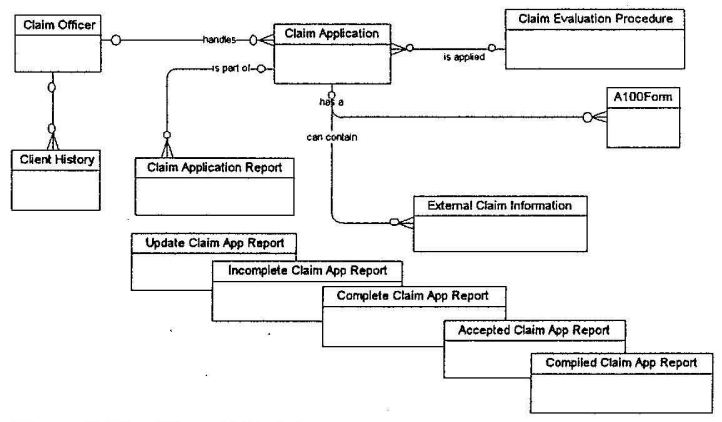

Figure 8 The Object Model

b) The Process Model

The process model (Figure 9) depicts the a process flow for the activity, "Compile Claim Application". This process flow is based on the following process description: "The Claim Application Report is received, whereafter the existence of the client is checked. This action can have the consequence of either registering the client as a new client, or retrieving the client's existing information from the computer database. Whenever this information is completed, a copy of the client information is produced".

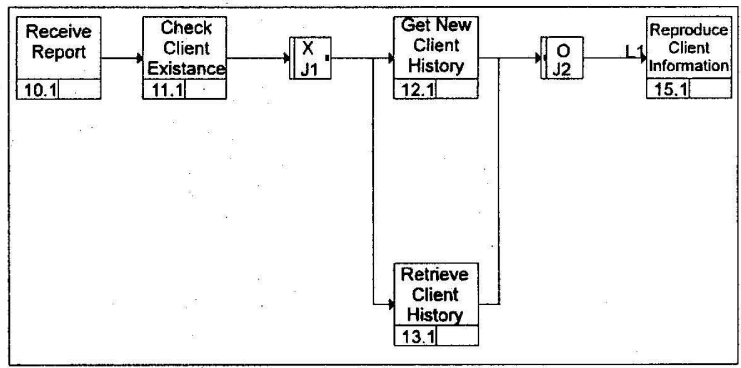

Figure 9 The Process Model

The Design Phase and Implementation Phase depends on the application of business techniques to improve the current process description of the claim application process. 


\subsection{The Open Solution Methodology Design Phase}

Simulation modelling is a powerful business technique which enhances the formulation of solutions to problems. For the purpose of demonstrating the integration between Simulation Modelling and the Open Solution Methodology, a simulation model is developed to study the process "Compile Claim Applications" (Figure 9). Table 4 displays an extract from the identified simulation objects and simulation types needed for the formulation of the simulation model specification sheet (Table 5).

\begin{tabular}{|c|c|c|}
\hline GNIT OF BEHAVIOUR: & OBJECTS & SIMULATION TYPES \\
\hline Receive report & $\begin{array}{l}\text { Claim Application } \\
\text { Claim Officer } \\
\text { Cómputer }\end{array}$ & $\begin{array}{l}\text { Entity } \\
\text { Resource } \\
\text { Location }\end{array}$ \\
\hline
\end{tabular}

Table 4 Simulation Object Classification for the "Compile Claim Application process

Five alternatives were tested with the simulation model:

i) Keep the current "Compile Claim Application" process as is.

ii) Appoint an additional claim officer to compile claim applications.

iii) Automate the complete "Compile Claim Application" process.

iv) Improve the reliability of the current computer infrastructure.

v) Combine alternative iii) and alternative iv).

Simulation results indicated that alternative v) provides the best solution whereby this solution will result in the processing of 150 claim applications per week and the utilisation of the claim officer and computer infrastructure rising to 90 per cent and 96 per cent respectively.

\subsection{The Open Solution Methodology Implementation Phase}

The development of training procedures demonstrates the implementation support that the Open Solution Methodology provides during the Implementation Phase. In this phase, the analyst and solution developers are concerned with the implementation of solutions, with the effect that training procedures need to be developed to train users to use these solutions. The following example illustrates an extract of a training procedure for the process "Compile Claim Application" (Table 6). The development of such a training procedure is based upon the Open Solution Methodology's Process Model, as the Process Model contains useful information about processes, procedures and task descriptions. 


\begin{tabular}{|c|c|c|}
\hline $\begin{array}{l}\text { SIMULATION } \\
\text { OBJECT }\end{array}$ & \multicolumn{2}{|c|}{ REILATED SIMULATION INFORMATION } \\
\hline \multirow[t]{2}{*}{ Claim Application } & \multicolumn{2}{|c|}{$\begin{array}{ll}\text { Arrival Time } & \\
\text { Batch size: } & 1 \\
\text { Inter-Arrival Time: } & \text { Normal(8,2) minutes } \\
\text { Arrival Point: } & \text { Receive Report }(10.1)\end{array}$} \\
\hline & \multicolumn{2}{|c|}{$\begin{array}{l}\text { Comment: } \\
\text { For the simulation object, "Claim application", arrivals are generated } \\
\text { in the "Compile Claim Application" process at UOB, "Receive } \\
\text { Report", with an inter-arrival time of Normal }(8,2) \text { minutes. }\end{array}$} \\
\hline \multirow[t]{2}{*}{ Claim Officer: } & \multicolumn{2}{|c|}{ Total Number Available: 1} \\
\hline & \multicolumn{2}{|c|}{$\begin{array}{l}\text { Comment: } \\
\text { For the current process, only one claim officer handles all claim } \\
\text { applications. }\end{array}$} \\
\hline Computer: & \multicolumn{2}{|c|}{$\begin{array}{l}\text { Number Available: } 1 \\
\text { Needs Setup } \\
\text { Setup Rules } \\
\text { 1. A setup is performed based on the number of operations the } \\
\text { computer system performs. The first setup is needed after five } \\
\text { operations, with follow-up setups between } 1000 \text { operation } \\
\text { intervals. }\end{array}$} \\
\hline \multirow{2}{*}{$\begin{array}{l}\text { Computer_ } \\
\text { Technician }\end{array}$} & \multicolumn{2}{|c|}{ Number available: 1} \\
\hline & \multicolumn{2}{|c|}{$\begin{array}{l}\text { Comment: } \\
\text { For the current process, only one computer technician is available. }\end{array}$} \\
\hline \multirow[t]{2}{*}{$\begin{array}{l}\text { JI XOR Logic } \\
\text { Junction }\end{array}$} & $\begin{array}{l}\text { Logic Type: } \\
\text { Branch: }\end{array}$ & $\begin{array}{l}\text { Probability } \\
\text { Get New Client History (0.5) } \\
\text { Retrieve Client History }(0.5)\end{array}$ \\
\hline & \multicolumn{2}{|c|}{$\begin{array}{l}\text { Comment: } \\
\text { Based upon a } 50 \% \text { probability, entities will be routed between the "Get } \\
\text { New Client History" UOB and the "Retrieve Client History" UOB. }\end{array}$} \\
\hline
\end{tabular}




\section{TRAINANG PROC CEDURE: RECEIVE CI AIM APPLICATION}

The training procedure is divided into the Process Diagram, Process Description, and Work Procedure sections.

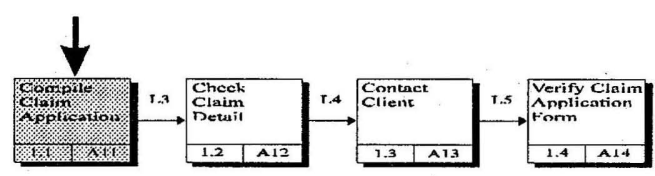

\subsection{Compile Claim Application}

Reference Numbers:

Activity Model: A11

Process Model: 1.1

\section{Description:}

The Compile Claim Application process is used to compile the necessary information in order to evaluate the claim application.

Task Description:

When the claim officer receives the claim application, the client's file containing the relevant history of the client, is retrieved. If it is a new client, the client's information is stored in the company's computer database.

\section{WORK PROCEDURE}

1. Receive the Claim Application Report.

2. Check to see whether the client is an existing client or a new client.

3. If the client is new:

- Register the client information in the database.

- Print Customer information.

4. If the client number is found:

- Print client history.

5. Attach Client history to Claim Application Report

\section{Table 6 Training Procedure}

\section{IMPLEMENTATION GUIDELINES}

The successful implementation of the Open Solution Methodology depends on the manner in which the methodology is applied to a given problem environment. The main consideration for the Open Solution Methodology implementation is the level of modelling detail required to solve a problem. This means that the Open Solution Methodology takes an open approach towards problem solving - applying the appropriate Open Solution Methodology models at the appropriate level of detail. 
The tailoring of the methodology addresses the appropriate level of detail which depends on the experience of the analyst to solve the problem. This means that depending on the problem, any combination of the three questions, "what?", "how?", and "who?" is used to determine which models are to be used to model the problem, and at which appropriate level of detail they should be implemented. The following guidelines are presented in order to determine which models should be used:

i) If the analyst needs to know "what?" is going on in the problem environment, the activity model is used.

ii) If the analyst needs to know "how?" something needs to be done, the process model is used.

iii) If the analyst needs to know "who?" should be doing the "how?", the object model is used.

\section{CONCLUSION}

Problems can be analysed and solved through the use of models. According to Arbor [1], the successful formulation and application of models rely on three elements, namely system knowledge, engineering judgement, and model-building tools. The Open Solution Methodology aims to capture system knowledge through the use of Open Solution Methodology models as model-building tools, while allowing the practitioner to apply engineering judgement in order to solve the problem. Based on this, the following benefits are gained by the application of the Open Solution Methodology:

i) Provides a formal and structured approach within which to solve problems.

ii) Provides the ability to comprehend and integrate all aspects of the problem environment.

iii) Provides the ability to incorporate team knowledge.

iv) Reduces the time required to analyse problems.

v) Provides a framework for the application of business techniques.

vi) Enhances the quality of solutions.

This article presents a generic problem-solving methodology which can be used to solve any type of business problem. By using the problem-solving approach, phases, models and methods of the Open Solution Methodology it is proved that a generic problem-solving methodology is feasible and practical for solving business problems.

\section{REFERENCES}

1. Arbor A, "Systematics: How systems really work and how the fail", 2nd ed. MI: The General Systematics Press, pp. 965. 